\title{
Patient safety and junior doctors: are we missing the obvious?
}

\section{Claire Lemer, Fiona Moss}

Correspondence to

Dr Claire Lemer, London Deanery; clairelemer@nhs.net
To cite: Lemer $C$, Moss $F$. BMJ Qual Saf 2013;22:8-10.
Doctors in postgraduate training posts are essential for delivery of acute care in the NHS. Arguably, amongst the most engaged and energetic in the health care workforce, they occupy an organisational space that lets them see good and bad practice and experience first hand both what happens when an organisation works well and the failings that all too often line up to cause harm to patients. And yet, these doctors are only marginally involved in the running of the organisations in which they work. Failure to involve such a key sector of the health care workforce in quality improvement initiatives does a disservice to doctors in training and the patients they care for so ubiquitously.

Leading quality improvement therefore requires not only clinical knowledge of effective interventions but also a clearly defined set of organisational skills and an understanding of organisational behaviours. Sir Donald Berwick articulated these skills two decades ago ${ }^{1} 2$ and the NHS institute for Innovation and Improvement now includes some of them in its Medical Leadership Competency Framework: demonstrating personal qualities, working with others, managing services, improving services, setting direction and demonstrating personal qualities. ${ }^{3}$ The Medical Royal Colleges and the General Medical Council, who set and approve speciality curriculums, recognise the importance of these skills which are referenced within curriculums and within guidance for practice. ${ }^{4}$

Most doctors in postgraduate training programmes do not formally acquire these skills as part of their clinical experience and training. A few work with clinical supervisors who are also clinical managers and so do learn about the skills for organisational change. For many, learning about this aspect of medical practice is concentrated within a single 'management courses' set apart from their clinical work and usually at the end of their training programme. Not surprisingly, many newly appointed consultants undoubtedly feel ill prepared for the organisational aspects of their work and are not equipped to lead quality and safety improvement initiatives. By separating learning about the clinical care of individual patients from learning about the care of the organisation and teams whose effective functioning underpin effective clinical care, the education system seems designed to produce precisely the results it delivers. That is, doctors who are relatively well prepared to look after individual patients but poorly prepared to make and support organisational changes crucial for continuous improvements in the quality and safety of care.

So, there is has been a clear gap between what we provide and what is needed. Recently, a number of discrete initiatives and projects have demonstrated the significant benefits of engaging doctors in training in quality improvement and change management within the hospitals or practices in which they work. A systematic review of the literature identified a numbers of educational programmes aimed at various levels of clinicians and which may improve clinical processes. ${ }^{5}$ In a recent survey, junior doctors who had taken part in such programmes reported a greater likelihood of improvement projects succeeding. ${ }^{6}$ However, these programmes are not universal and many doctors in training are still not able to access them. Furthermore, a recent review of training on improvement, by The Health Foundation suggests that few data exist to identify which sort of programme is most effective and indeed, at whom this should be aimed.

The study reported by Durani et $a l^{8}$ highlights the degree to which attitudes to quality improvement and patient safety 
vary subtly between seniority levels and specialties within UK training grades. Among 527 junior doctors who completed the survey, self-declared knowledge in patient safety concepts was high, though 60\% acknowledged not understanding basic concepts such as the distinction between active failures and latent conditions (60\%) with respect to causes of adverse events. Almost all (99\%) agreed with the statement 'Even the most experienced and competent doctors make errors'. And, only $8 \%$ of respondents agreed with the statement: 'If people try hard enough, they will not make any errors'. Interestingly, senior trainees (vs junior trainees) and surgical trainees (vs medical trainees) far more often agreed with the statement 'Medical error is a sign of incompetence' $(\mathrm{p}<0.01)$.

On the one hand, these results might seem disheartening. Despite over a decade of widespread attention to the systems aspects of patient safety-in major medical journals, educational curricula, and improvement projects at local, regional and national levels-a significant subset of respondents appear to hold on to the traditional view that errors generally reflect individual incompetence rather than, for instance, predictable results of poorly designed systems. On the other hand, that junior doctors tended not to hold this view may attest to the effectiveness of the various educational efforts related to patient safety and quality improvement. These efforts may not have had as much impact as one would have liked on senior trainees, but the fact that the most junior trainees evince the desired understanding of individual fallibility and the causes medical error may suggest that educational efforts are succeeding. That these views vary across specialties highlights the need to tailor educational programmes to the clinical audience (and apparently to the grade of training as well).

\section{BUILDING ON CURRENT SUCCESSES}

In the London Darzi Programme, doctors in training work for a year with a senior medical managers on system change; a quality improvement project and work with their organisations to increase capacity for locally based leadership training and are supported by a bespoke leadership course. ${ }^{9}$ This programme has now been extended to other clinical professionals. The North West Deanery has developed a programme, the North West Buddy Scheme (where doctors rotate between managerial and clinical posts). All of these programmes seem to have wide-ranging benefits with evidence that they reach beyond the individuals directly involved and feedback has been universally positive. Moreover, the enthusiasm and energy of doctors who have participated in these programmes has inspired many others to set up smaller local initiatives. Indeed, it seems that no longer are doctors in training prepared to wait to be invited to step up to into (organisational) roles' and some are now acting as 'agents of change' and developing their own improvement initiatives ${ }^{10}$ - for example, Prepare to Lead, which pairs junior doctors with senior manager mentors.

Doctors in training are also addressing other elements crucial to embedding quality improvement within training and the workplace. Traditionally, doctors in training in the UK have had to undertake 'audits' as part of their annual assessments. Now, through the work of doctors in training who understand what it takes to make change, this is being amended in curricula to 'quality improvement work'. Support of senior doctors and managers is hugely important and has helped many of these initiatives. However, this is balanced by the problems that some doctors in training face when working with senior colleagues who, unlike them, have not had training in organisational change and quality improvement. This has stimulated trainees to lead the creation of training programmes for more senior colleagues to help bridge this gap. Perhaps though this needs to go further, to include supporting those in educational supervision roles so that they can help to act as conduits for escalating and resolving issues that arise during doctors in training's efforts at improvement.

Similarly, in addition to training the trainers about how to do improvement work, future-training efforts need to focus on how to publish improvement work. Recent conferences at which Junior Doctors were able to present their improvement work, such as the Faculty of Medical Leadership and Management Conference have seen a very high response rate. Yet little of this seems to make it into journals, despite guidelines, for example Standards for Quality Improvement Reporting Excellence existing. ${ }^{11}$ Perhaps, in addition to training around how to do quality improvement, future efforts need to focus on dissemination of learning too.

The financial climate in the NHS is such that to succeed in preserving the NHS ingenuity and a myriad of small improvements are needed. Programmes that maximise doctors in training roles in this work need to be nurtured, however they need to learn from studies such as that of Durani et al, which point out the nuanced different attitudes to improvement that are in existence within the ranks of doctors in training. Early efforts have shown evidence of success, but supporting senior professionals to assist junior efforts, continuing to spread programmes of learning more widely (indeed to include multiprofessional approaches) and focusing on how to publish work are perhaps areas for further development. If we fail to utilise the talents and enthusiasm of our doctors in training then we fail current and future patients.

Funding None.

Competing interests None. 
Provenance and peer review Commissioned; internally peer reviewed.

\section{REFERENCES}

1 Berwick DM, Enthoven A, Bunker JP. Quality management in the NHS: the doctor's role 2. BMJ 1992;304:304-8.

2 Berwick DM, Enthoven A, Bunker JP. Quality management in the NHS: the doctor's role 1. BMJ 1992;304:304-8.

3 Medical Competency Framework. http://www.institute.nhs.uk/ assessment_tool/general/

medical_leadership_competency_framework_-_homepage.html Accessed 16th November 2012

4 GMC approved Curricula. http://www.gmc-uk.org/education/ approved_curricula_systems.asp Accessed 16th November 2012

5 Wong BM, Etchells EE, Kuper A, et al. Teaching quality improvement and patient safety to trainees: a systematic review. Acad Med 2010;85:1425-39.
6 Gilbert A, Hockey P, Vaithianathan R, et al. Perceptions of junior doctors in the NHS about their training: results of a regional questionnaire. BMJ Qual Saf 2012;21:234-8.

7 Health Foundation Evidence Scan Quality improvement training for healthcare professionals. http://www.health.org.uk/ publications/ quality-improvement-training-for-healthcare-professionals/

8 Durani P, Dias J, Singh H, et al. Junior doctors and patient safety: evaluating knowledge, attitudes and perception of safety. BMJ Qual Saf 2013.

9 Darzi Fellowships. http://www.leadership.londondeanery.ac.uk/ home/fellowships\%20in\%20clinical\%20education

10 Swannick T. Junior doctors: the best kept secret in the NHS. Postgrad Med J 2012;88:117-8.

11 Ogrinc G, Mooney SE, Estrada C, et al. The SQUIRE (Standards for QUality Improvement Reporting Excellence) guidelines for quality improvement reporting: explanation and elaboration. Qual Saf Health Care 2008;17(Suppl 1):i13-32. 